\title{
O MOVIMENTO DE PAIS E MÃES PELA EDUCAÇÃO INTEGRAL EM MANAUS: ARTICULANDO A PESQUISA NOS/DOS/COM OS COTIDIANOS COM A LUTA POR UMA EDUCAÇÃO DE QUALIDADE SOCIALMENTE REFERENCIADA
}

SIMÕES, Ceane Andrade*

BOCCHINI, Ana Gouvea ${ }^{* *}$

MACEDO, Regina Coeli Moura de ${ }^{* * *}$

\begin{abstract}
RESUMO
Neste texto procuramos discutir a disputa pelo caráter público da educação e suas possibilidades emancipatórias, por meio do registro e da reflexão sobre a trajetória de atuação de um movimento social constituído por pais e mães em Manaus (Coletivo Escola Família Amazonas - CEFA), que vem requerendo um maior espaço de participação na reformulação e implementação da Política Pública de Educação Integral no município junto ao poder público municipal, representado pela Secretaria Municipal de Educação - SME, e nos espaçostempos das escolas públicas.Tal esforço se insere no campo teórico-políticoepistemológico das pesquisas nos/dos/com os cotidianos, na perspectiva de dar visibilidade às práticas sociais de natureza emancipatória que estão se desenvolvendo na ampliação da articulação dialógica entre pais e mães-educadores/educadoras-dirigentes da educação pela ofertada de educação integral na rede pública municipal de ensino de Manaus e na busca de "inéditos viáveis", conforme Paulo Freire, que incorporem a esperança na transformação da educação e na valorização do seu caráter público - em que pese a crise democrática e a retração dos investimentos na educação pública, entre outras questões que estamos atravessando no contexto brasileiro. Mesmo se tratando de um movimento recente e em busca de consolidação, podemos avaliar a atuação desse coletivo de maneira positiva na medida em que busca reposicionar o sentido e a força da participação na educação pública, assentada na vivência democrática e na busca de qualidade da educação socialmente referenciada.
\end{abstract}

Palavras-Chave: Movimento social. Educação integral. Cotidiano escolar. Educação pública.

\footnotetext{
* Graduada em Pedagogia pela Universidade Federal do Amazonas - UFAM. Mestranda em Educação pela Universidade do Estado do Rio de Janeiro - UERJ. Membro do Grupo de Pesquisa Redes de conhecimentos e práticas emancipatórias no cotidiano escolar . Vice-coordenadora do Coletivo Escola Família Amazonas - CEFA. Professora da Universidade do Estado do Amazonas - UEA/Manaus/AM/Brasil. E-mail: ceane@ uea.edu.br
** Mestre em Ciências do Ambiente e Sustentabilidade na Amazônia pela Universidade Federal do Amazonas - UFAM. Graduada em Pedagogia pela Universidade Estadual Paulista - Júlio de Mesquista Filho - UNESP. Coordenadora do Coletivo Escola Família Amazonas - CEFA - Manaus/AM/Brasil. E- mail:anagouveab@gmail.com

\footnotetext{
${ }^{* * *}$ Doutora em Educação pela Universidade do Estado do Rio de Janeiro - UERJ (2014). É professora dos anos iniciais do Ensino Fundamental do Colégio Pedro II, Unidade São Cristóvão - Rio de Janeiro/RJ/Brasil. Membro do Grupo de Pesquisa Redes de conhecimentos e práticas emancipatórias no cotidiano escolar. E-mail: regininhamacedo@uol.com.br
} 


\title{
e-Curriculum
}

Programa de Pós-Graduação em Educação: Currículo

\section{PARENT'S MOVEMENT FOR INTEGRAL EDUCATION IN MANAUS: ARTICULATING RESEARCH IN/OF/WITH THE SCHOOL ROUTINE AND THE FIGHT FOR EDUCATION OF QUALITY AND SOCIALLY REFERENCED}

\author{
SIMÕES, Ceane Andrade* \\ BOCCHINI, Ana Gouvea ${ }^{* * *}$ \\ MACEDO, Regina Coeli Moura de ${ }^{* * *}$
}

\begin{abstract}
We seek to discuss the dispute over the public nature of education and its emancipatory possibilities, through the recording and reflection on the trajectory of action of a social movement constituted by fathers and mothers in the city of Manaus (School-Family Collective of Amazonas - CEFA) which has been seeking a greater participation in the reformulation and implementation of the Public Policy of Integral Education together with the local public authority, represented by the Municipal Secretariat of Education-SEMED, and in the time-space of the public schools. This effort is inserted in the theoreticalpolitical-epistemological field of investigations in /of /with schoolroutine with the perspective of giving visibility to the social practices of an emancipatory nature that are being developed during the dialogical articulation between parents-educators /managers-educatorsby the offer of integral education in the municipal public schools of Manaus and the search for "viable unpublished" that, according to Paulo Freire, incorporate the hope in the transformation of the education and in the valorization of its public character - in spite of the democratic crisis and the retraction of the investments in the public education, among other things, that we cross in the Brazilian context. Although young, the movement is looking for its consolidation and we can positively evaluate its action in the measure that seeks to reposition the sense and the force of the participation in the public education, based on the democratic experience and the search education of quality and socially referenced.
\end{abstract}

Keywords: Social movement. Integral education. School routine. Public education.

${ }^{*}$ Graduate in Pedagogy by Federal University of Amazonas - UFAM and Master degree candidate in the University of Rio de Janeiro State - UERJ. Member of the research group on Networks of Knowledge and Emancipatory Practices in the Everyday School. Vice coordinator of the School-Family Collective of Amazonas - CEFA and Graduate Professor in University of Amazonas State - UEA/Manaus/AM/Brazil.E-mail: ceane@uea.edu.br

** Master degree in Environmental Sciences and Sustainability in the Amazon by Federal University of Amazonas UFAM. Graduate in Pedagogy by the University of São Paulo state - Julio de Mesquita Filho - UNESP. Coordinator of the School-Family Collective of Amazonas - CEFA - Manaus/AM/Brasil. E-mail: anagouveab@gmail.com

*** PhD in Education by University of Rio de Janeiro State - UERJ (2014). Teacher on initial years in the Pedro II School, São Cristovão Unit - Rio de Janeiro/RJ/Brazil. Member of the research group on Networks of knowledge and Emancipatory Practices in the Everyday School. E-mail: regininhamacedo@uol.com.b

$r$

Ceane ANDRADE,Ana Gouvea BOCCHINI, Regina Coeli Moura de MACEDO O movimento de pais e mães pela ecucação integral em Manaus: articulando a pesquisa nos/dos/com os cotidianos com a luta por uma educação de qualidade socialmente referenciadal. 


\title{
$e$-Curriculum
}

Programa de Pós-Graduação em Educação: Currículo

\section{EL MOVIMIENTO DE PADRES Y MADRES POR LA EDUCACIÓN INTEGRAL EN MANAUS: ARTICULANDO LA INVESTIGACIÓN EN/ DE/ CON LOS COTIDIANOS CON LA LUCHA POR UNA EDUCACIÓN DE CALIDAD Y SOCIALMENTE REFERENCIADA}

\author{
SIMÕES, Ceane Andrade* \\ BOCCHINI, Ana Gouvea ${ }^{* *}$
}

RESUMEN

MACEDO, Regina Coeli Moura de ${ }^{* * *}$

En este texto buscamos discutir la disputa por el carácter público de la educación y sus posibilidades emancipadoras, por medio del registro y de la reflexión sobre la trayectoria de actuación de un movimiento social constituido por padres y madres en la ciudad de Manaus (Colectivo Escuela Familia del Amazonas - CEFA), que viene buscando una mayor participación en la reformulación $e$ implementación de la Política Pública de Educación Integral junto al poder público municipal, representado por la Secretaría Municipal de Educación - SEMED, y en los espaciostiempos de las escuelas públicas. Este esfuerzo se inserta en el campo teórico-político-epistemológico de las investigaciones en /de/con los cotidianos, con la perspectiva de dar visibilidad a las prácticas sociales de naturaleza emancipadora que se están desarrollando durante la articulación dialógica entre padres y madres-educadores / educadores-dirigentes por la oferta de la educación integral en las escuelas públicas municipales de Manaus y en la búsqueda de "inéditos viables" que, según Paulo Freire, incorporen la esperanza en la transformación de la educación y en la valorización de su carácter público - en que pese a la crisis democrática y la retracción de las inversiones en la educación pública, entre otras cuestiones, que atravesamos en el contexto brasileño. Aunque sea un movimiento reciente en busca de su consolidación, podemos evaluar de manera positiva su actuación en la medida que busca reposicionar el sentido y la fuerza de la participación en la educación pública, asentada en la vivencia democrática y en la búsqueda de calidad de la educación socialmente referenciada.

Palabras clave: Movimiento social. Educación integral. Cotidiano escolar. Educación pública.

\footnotetext{
* Pedagoga graduada en la Universidad Federal del Amazonas - UFAM. Estudiante de maestria en Educación en la Universidad Estatal de Rio de Janeiro - UERJ. Miembro del grupo de investigaciones Redes de Conocimiento y Prácticas Emancipatorias en el Cotidiano Escolar. Vice coordinadora del Colectivo Escuela Familia Amazonas CEFA. Profesora de la Universidad Estatal del Amazonas - UEA/Manaus/AM/Brasil. E-mail: ceane@uea.edu.br

** Mestre em Ciências do Ambiente e Sustentabilidade na Amazônia pela Universidade Federal do Amazonas UFAM. Graduada em Pedagogia pela Universidade Estadual Paulista - Júlio de Mesquista Filho - UNESP. Coordenadora do Coletivo Escola Família Amazonas - CEFA - Manaus/AM/Brasil. E-mail: anagouveab@gmail.com

*** Doctora en Educación por la Universidad Estatal de Rio de Janeiro - UERJ (2014). Profesora de primer grado en el Colégio Pedro II, Unidad São Cristóvão - Rio de Janeiro/RJ/Brasil. Miembro del grupo de investigaciones Redes de Conocimiento y Prácticas Emancipatorias en el Cotidiano Escolar. E-mail: regininhamacedo@uol.com.br
} 


\section{e-Curriculum}

Programa de Pós-Graduação em Educação: Currículo

\section{INTRODUÇÃO}

. Faz pouco tempo, em uma entrevista que me fizeram em Madri, um jornalista me falou: "Lendo os seus livros sinto que tem um olho microscópico e outro olho telescópico". Eu achei uma boa definição das minhas intenções, do que eu gostaria de fazer escrevendo, ser capaz de olhar o que não se olha, mas que merece ser olhado, as pequenas, as minúsculas coisas da gente anônima, da gente que os intelectuais costumam desprezar. Esse micromundo onde eu acredito que se alimenta de verdade a grandeza do universo e ao mesmo tempo ser capaz de contemplar o universo através do buraco da fechadura, ou seja, a partir das pequenas coisas ser capaz de olhar as grandes, os grandes mistérios da vida, o mistério da dor humana, mas também o mistério da persistência humana nesta mania, às vezes inexplicável, de lutar por um mundo que seja a casa de todos e não a casa de pouquinhos e o inferno da maioria e outras coisas mais

Eduardo Galeano

A longa epigrafe ${ }^{i}$ do jornalista e escritor uruguaio Eduardo Galeano nos ajuda no exercício de olhar as pequenas e as grandes coisas (da vida, do universo, das práticas sociais etc). É um convite a pensar nas relações entre as coisas minúsculas e grandiosas e ter a oportunidade de perceber a si mesmo nessas relações; a deter o olhar naquilo que nos parece invisível, mas também ser capaz lançar esse mesmo olhar, ainda que num vislumbre, para outras possibilidades mais amplas do existir. É esse o desafio lançado a quem busca compreender as possibilidades existentes no interior da escola (pública) e também naquilo que está "fora" dela. Desafio esse advindo da necessidade de pensarfazer ${ }^{i i}$ educação no dentrofora, nas relações macro/micro, e de refletir sobre como a prática participativa pode mobilizar essas ações pequenas e grandiosas nestes tempos de perplexidade contínua em todas as esferas da vida social, em que muitas vezes nos falham as forças para agir no presente, a esperança para projetar o futuro e a coragem para revisitar o passado.

Considerando esses desafios, neste trabalho procuramos discutir a disputa pelo caráter público da educação e suas possibilidades emancipatórias, por meio do registro e da reflexão sobre a trajetória de atuação de um movimento social constituído por pais e mães ${ }^{\text {iii }}$ em Manaus que vem requerendo um maior espaço de participação na reformulação e implementação da Política Pública de Educação Integral no município junto ao poder público municipal, 


\section{e-Curriculum}

Programa de Pós-Graduação em Educação: Currículo

representado pela Secretaria Municipal de Educação- SME, e nos espaçostempos das escolas públicas. Tal esforço se insere no campo teórico-político-epistemológico das pesquisas nos/dos/com os cotidianos, na perspectiva de dar visibilidade às práticas sociais de natureza emancipatória que estão se desenvolvendo na ampliação da articulação dialógica entre pais e mães-educadores/educadoras-dirigentes da educação pela oferta da educação integral na rede pública municipal de ensino de Manaus - em que pese a crise democrática e a retração dos investimentos na educação pública, entre outras questões que estamos atravessando no contexto brasileiro.

Esse movimento de pais e mães ${ }^{\text {iv }}$ tem pautado o seu ativismo na luta pela qualidade da educação pública, partindo dos princípios da autonomia pedagógica e da gestão democrática das unidades escolares, bem como do reposicionamento das formas de participação nos cotidianos das escolas de educação integral, recentemente em funcionamento na rede pública municipal de ensino. Necessariamente, isso reflete o tipo de organização experienciada pelo próprio coletivo, corporificada em relações que aprofundam o fazer participativo/colaborativo, a horizontalidade e a partilha de autoridade, movido pela necessidade de questionar o modelo de educação hegemônica. Com isso, no interior do movimento e na relação com as escolas apoiadas, passam a ser criadas novas possibilidades para pensar a educação com qualidade socialmente referenciada, vinculada, portanto, aos valores, interesseses e saberes dos sujeitos implicados no seu cotidiano.

\section{OS CAMINHOS PERCORRIDOS: TECENDO UM[A] [A]MANHÃ.}

\footnotetext{
Um galo sozinho não tece uma manhã: ele precisará sempre de outros galos. De um que apanhe esse grito que ele e o lance a outro; de um outro galo que apanhe o grito de um galo antes e o lance a outro; e de outros galos que com muitos outros galos se cruzem os fios de sol de seus gritos de galo, para que a manhã, desde uma teia tênue, se vá tecendo, entre todos os galos.

João Cabral de Melo Neto
} 


\section{e-Curriculum}

Programa de Pós-Graduação em Educação: Currículo

O celebrado poema de João Cabral de Melo Neto tem feito cada vez mais sentido num momento em que está posta para nós, educadores/educadoras e sociedade em geral, a necessidade de repensar e aprofundar práticas democráticas participativas, uma vez que temos presenciado as limiações do modelo democrático liberal, assentado estritamente na representatividade e no direito ao voto. Ante as tensões políticas que têm se radicalizado desde 2013 e, de maneira mais específica, após o ano de 2014 no Brasil, é oportuno que a sociedade se organize em torno de suas pautas reivindicatóricas na busca de justiça social para todos/todas. No campo da educação, reconhecemos a necessidade de aprofundamemento da discussão sobre a sua qualidade, necessidades e rumos, de forma ampliada e implicada, além de, verdadeiramente, tornar as escolas estatais em escolas públicas.

No que toca ao seu caráter público, concordamos com Masschelein e Simons (2014, p. 114) no sentido de que a escola é pública não pela forma como é financiada, mas por ser “[...] um espaço e tempo de jogo, um espaço público, e um espaço onde o conhecimento é colocado à nossa disposição e liberado". É público no sentido daquilo que é tornado comum; portanto, constituído pelo o que é comunal, do que é para todos e em que todos participam, o que também lhe confere teor democrático. Mas, além disso, a disputa pelo caráter público da educação é a própria disputa pelas concepções, práticas e condições em que se realiza a formação humana e pelas possibilidades contidas nesse ato dialógico/utópico/ideológico, considerando o que o educador Paulo Freire chamou de "inéditos viáveis". Ou do que Santos (2004) entende como o "ainda-não", daquilo que se inscreve no presente e o dilata, criando possibilidades outras e/ou gerando possibilidades de politização dos espaços estruturais (o espaço da cidadania; o espaço doméstico; o espaço da produção e o espaço mundial). Nesse sentido, "politizar significa identificar relações de poder e imaginar formas práticas de as transformar em relações de autoridade partilhada" (SANTOS, 1997, p. 271).

A (re)politização dos quatro espaços estruturais, de acordo com Santos (1997), tem sido promovida (mesmo que com limitações) pelos novos movimentos sociais (movimentos emancipatórios, bastante heterogêneos) e pela criação de novos sujeitos sociais de base transclassista - o surgimento dos movimentos estudantis, por exemplo. Ou seja, pelas novas formas de cidadania coletiva que têm vindo a propor a experimentação social e a formulação de 


\section{e-Curriculum}

Programa de Pós-Graduação em Educação: Currículo

alternativas mais ou menos radicais ao modelo de desenvolvimento econômico e social do capitalismo, sobretudo na América Latina, o que requer a socialização e a aprendizagem cultural de outros modelos de desenvolvimento social, político e econômico.

Quanto a pensar outras possibilidades de educação, concordamos com Streck (2010), para quem os movimentos sociais estão na base de uma educação popular, sendo que a esta se impõe o desafio de se recriar. Para esse autor:

A educação popular tem como uma de suas marcas acompanhar o movimento de classes, grupos e setores da sociedade que entendem que o seu lugar na história não corresponde aos níveis de dignidade a que teriam direito. Isso pode significar a reivindicação de espaço na estrutura existente, mas pode também representar o engajamento na luta por rupturas e pela busca de novas possibilidades de organização da vida comum (STRECK, 2010, p. 300).

Portanto, apostamos que os movimentos sociais - a exemplo do coletivo de pais e mães que aqui apresentamos e do qual participamos - animados pelo fazerpensar possibilidades de escola pública, a partir de um horizonte democrático e plural nas suas redes cotidianas de conhecimento, também estão propondo a realização de uma educação popular.

Essa discussão é necessária como ponto de partida para compreender o movimento constituído por pais e mães e, mais recentemente, contando com a participação de educadores/educadoras e de pessoas que se sentiram mobilizadas a discutir coletivamente possibilidades de educação contra-hegemônica no contexto da educação pública na cidade de Manaus.

O Coletivo Escola Família Amazonas - CEFA surgiu em abril do ano de 2015, quando as inquietações sobre a educação que nossos/nossas filhos/filhas (a maioria na primeira infância) vinham experienciando nas escolas privadas de Manaus já não podiam mais ficar restritas ao espaço doméstico. Naquela ocasião, as insatisfações e os tensionamentos visíveis na relação com as escolas começaram a ser expressos nos encontros sociais entre amigos. Nesses espaçostempos de conversa, as questões do passado e do presente em torno da educação tradicional experimentada por nós, pais e mães, e a vivida pelos/pelas nossos/nossas filhos/filhas passou a ser um tema corriqueiro, mobilizando um "pensar sobre" mais engajado. 


\section{$e$-Curriculum}

Programa de Pós-Graduação em Educaçãa: Currículo

A partir daí, organizamos um grupo de e-mail para o prolongamento das nossas conversas e a mobilização interna, especialmente para a organização e o registro das reuniões regulares, para a troca de informações, textos e notícias sobre experiências educativas outras, especialmente aquelas norteadas por concepções mais libertárias de homem e de sociedade. A Escola da Ponte, em Portugal, ou experiências brasileiras como o Projeto Âncora e as Escolas Municipais de Ensino Fundamental - EMEF Campos Sales e Desembargador Amorim Lima, passaram a ser nossas fontes de inspiração, e seus idealizadores, nossos interlocutores diretos sobretudo no que diz respeito às potencialidades na ressignificação dos espaçostempos educativos na perspectiva da educação integral vincada na vivência de práticas democráticas em seu interior, estimulando uma maior participação da comunidade local nas decisões pedagógicas e administrativas das escolas e na experiência de relações mais horizontais e solidárias entre os sujeitos como constitutivas dos seus processos formativos, gerando práticas curriculares articuladas aos seus interesses e necessidades.

A educação integral passou a ser, para o CEFA, o conceito que conectava as nossas discussões, na medida em que articulava a formação humana com as linguagens e os desejos dos sujeitos implicados (crianças, jovens e adultos) para a garantia de diversas aprendizagens. Ou seja, como articulador dos espaçostempos de escolarização com os espaçostempos da vida, o que anuncia o seu caráter político-pedagógico.

Nas férias escolares do ano de 2015, diante do "o que fazer com os/as nossos/nossas filhos/filhas nesse período?" e já animados pela necessidade de revermos as nossas práticas educativas como pais e mães e de proporcionar espaços lúdicos e de liberdade para as crianças experimentarem o mundo, resolvemos organizar coletivamente uma colônia de férias itinerante, que consistiu em, a cada dia das férias, uma das famílias envolvidas receber o grupo das crianças em suas casas, resultando em momentos prazerosos de interação e novas possiblidades de diálogo entre nós. Assim surgiu uma primeira ideia, ainda que nada estivesse muito claro, da fundação de uma escola de educação integral comunitária. Mas, o que isso realmente representaria: "solução" ou "isolamento"? Estaria subjacente aí o não enfrentamento das questões educacionais mais amplas ou coisa que o valha? Não tardou para que nos apercebessemos da necessidade de dialogar com outros atores. Surgiu daí a ideia de mobilizar a sociedade por meio de um 


\section{e-Curriculum}

Programa de Pós-Graduação em Educação: Currículo

seminário. Mas, como realizá-lo de modo a ampliar o espaço de discussão e de participação de outros pais e mães e educadores/educadoras? É nessa ocasião que, em meados do ano de 2015, começamos os primeiros contatos com os dirigentes da Secretaria Municipal de Educação de Manaus (SME) em busca de parcerias.

Os diálogos entre o nosso coletivo e os educadores da SME acerca de uma educação de qualidade social pautada nos princípios da gestão democrática, da autonomia da escola e de uma educação transformadora foram se estabelecendo processualmente, mas tiveram como ponto de partida a realização do seminário "Mudar a Escola, Melhorar a Educação: Transformar Vidas", realizado nos dias 31/07 e 01/08/2015, com a presença dos educadores José Pacheco (educador português, fundador da Escola da Ponte), Braz Nogueira (então diretor da EMEF Campos Sales, referência pela experiência de educação democrática que vem se desenvolvendo em torno da cultura de paz e do bairro educador em Heliópolis, uma das maiores comunidades de São Paulo), e Helena Singer (então assessora especial do Ministério da Educação/Secretaria de Educação Básica, onde coordenava o Grupo de Trabalho de Criatividade e Inovação na Educação). Na ocasião, foram também apresentadas iniciativas do próprio estado do Amazonas que já vinham produzindo ações inovadoras na educação, como o Projeto Verde, realizado em comunidades ribeirinhas; o Projeto AFRA - Árvores Frutíferas da Amazônia, em uma escola municipal de Manaus, e a Escola Páamali - escola indígena Baniwa do Alto Rio Negro.

O evento contou com a participação de cerca de trezentos educadores da rede municipal de ensino. A partir desse seminário, alguns/algumas educadores/educadoras manifestaram o desejo de pensar sobre o trabalho que já vinham realizando e imaginar outras possibilidades no seu fazerpensar a escola, sendo este, de fato, um dos objetivos do encontro. E, muito embora não tivessem sido poucas as pessoas que se animaram com essa discussão, logo começaram a ser anunciados os limites a serem enfrentados em relação à cultura das escolas, à gestão burocrática da SME ou em relação às próprias adversidades evidenciadas pela degradação das condições objetivas de vida dos estudantes e de suas famílias e pela precarização dos espaços escolares, no contexto de uma rede municipal de ensino composta por mais de quinhentas unidades escolares, algumas das quais funcionando em prédios alugados e sem infraestrutura condizente com o trabalho educativo. 


\section{e-Curriculum}

Programa de Pós-Graduação em Educação: Currículo

Tal situação, constatada também após uma série de visitas às escolas públicas ${ }^{\mathrm{v}}$ manauaras, gerou certo desânimo entre os membros do CEFA, mesmo porque havia uma intenção, amadurecida processual e conscientemente, de matricularmos os nossos/nossas filhos/filhas nessas escolas públicas. Por outro lado, o movimento se ampliou com o ingresso de educadores/educadoras (da educação básica e de universidades públicas) no coletivo. Disso decorreu, progressivamente, a intensificação dos nossos encontros em termos de frequência e de temas discutidos. Ainda nesse período, realizamos uma oficina com representantes das escolas que conheceram o movimento por meio do seminário. Nessa oficina, entendemos que era importante saber como as escolas se "viam" e o que "sonhavam" para si. Foi, nesse sentido, um espaço de escuta dos/das educadores/educadoras, mas distante daquilo que almejávamos em termos de uma ação mais concreta para a educação integral no município, posto que isso demandava também o aprofundamento das ações junto aos dirigentes municipais, na cobrança por mais atenção ao tema.

Durante o segundo semestre de 2015 implementamos novas ações ${ }^{\text {vi }}$ no sentido de continuar mobilizando a sociedade manauara em torno de pensar sobre a "educação transformadora". Naquela ocasião começaram a ser intensificados os movimentos de resistência dos secundaristas de São Paulo em relação à "reorganização" das escolas imposta pelo governo daquele estado. E esse foi um assunto que mereceu atenção de todos/todas nós, que reivindicávamos uma incidência maior na formulação das políticas locais e a vivência democrática e participativa no dentrofora das escolas públicas.

No final do ano de 2015, buscamos criar também mais oportunidades de diálogo com as dirigentes da SME em torno da discussão de pedagogias que considerassem outras possibilidades de vivência de temposespaços educativos. Nesse sentido, alguns parceiros foram se agregando a essa pauta, como as Aldeias Infantis S.O.S (em Manaus), organização não governamental que vem realizando um trabalho socioeducativo de bastante lastro com crianças em situação de risco social, já tendo anteriormente firmado parceria com a SME; o Centro de Referências em Educação Integral ${ }^{\text {vii }}$ e a Fundação SM, na pessoa da Profa. Pilar Lacerda, ex-secretária nacional de Educação Básica do MEC.

Ceane ANDRADE,Ana Gouvea BOCCHINI, Regina Coeli Moura de MACEDO O movimento de pais e mães pela ecucação integral em Manaus: articulando a pesquisa nos/dos/com os cotidianos com a luta por uma educação de qualidade socialmente referenciadal. 


\section{$e$-Curriculum}

Programa de Pós-Graduação em Educação: Currículo

A nossa articulação com esses atores e a proposição de um projeto à SME para a fundação de uma escola de educação integral foram decisivos para a abertura da primeira escola de educação integral vinculada à rede municipal de ensino, com início de funcionamento no ano de 2016, e para a reformulação da Proposta Pedagógica para Escolas de Tempo Integral, ainda não implementada até aquele momento. É oportuno lembrar que a ampliação da oferta de escolas em tempo integral está estabelecida como uma das metas expressas no Plano Nacional de Educação, Lei n. 13.005, de 25/06/2014 (BRASIL, 2014) e, por conseguinte, no Plano Municipal de Educação de Manaus, Lei. N. 2.000, de 24/06/2015 (MANAUS, 2015), mas não estava sendo atendida pelo poder público municipal para além das ações abarcadas pelo Programa Federal "Mais Educação". Em vista disso, essa pareceu uma ocasião incontornável à SME para a abertura às experiências educativas em uma escola de jornada ampliada. No caso específico, tratava-se da conversão de uma escola ${ }^{\text {viii }}$ já em funcionamento em meio período para tempo integral e, simultaneamente, a revisão e implementação de uma política de educação integral para o município.

Como sabemos, e vivemos as consequências até o presente momento, o ano de 2016 foi o ápice de enormes turbulências no cenário social e político, culminado com o golpe parlamentarjurídico-midiático que destituiu a presidenta eleita Dilma Rousseff (PT) e que na sequência operou o desmonte significativo das políticas públicas voltadas à garantia dos direitos sociais. Apesar desse cenário (e com esse cenário), continuamos em nível local com a nossa atuação, considerando a necessidade de apoiar e estimular as mudanças que seriam realizadas na primeira escola de educação integral vinculada à SME e continuando a pressionar essa instância para a abertura (incorporação) de outras escolas de ensino fundamental e de educação infantil ao longo de 2016. Em abril desse mesmo ano, participamos do processo de implantação da segunda escola de educação integral vinculada à SME e da incorporação de um Centro Municipal de Educação Infantil que, não oficialmente, já vinha desenvolvendo ações de educação integral nas suas práticas cotidianas.

No campo das lutas mais amplas, num cenário de intensificação da crise política e da instauração de reformas prejudiciais à educação pública, participamos de atividades com estudantes do movimento de ocupação na Universidade do Estado do Amazonas, especialmente 


\section{e-Curriculum}

Programa de Pós-Graduação em Educação: Currículo

com estudantes dos cursos de licenciatura dessa universidade, apoiando o movimento de ocupação e aprendendo junto com eles. Também no processo das eleições municipais em 2016, propusemos a realização de um debate sobre o tema "Os desafios da Educação em Manaus" com candidatos à câmara de vereadores que se identificavam como educadores ou adotavam a educação pública como bandeira principal em suas campanhas eleitorais.

No contexto de nossa pauta específica - a educação integral - se tornava cada vez mais clara para nós a necessidade de valorização e implicação dos praticantes das escolas e do alargamento da vivência democrática em seu interior. Com o ingresso de nossos/nossas filhos/filhas nas três escolas municipais apoiadas, nossa atuação se intensificou por meio da participação nas atividades cotidianas das escolas, dos encontros para estudo e com a organização de uma viagem-formativa da qual participaram vinte educadoras (dessas escolas) às escolas públicas e organizações não governamentais no estado de São Paulo que protagonizaram mudanças substantivas no seu currículo, a exemplo da EMEF Campos Sales, da EMEF Amorim Lima e da Escola Municipal de Educação Infantil Nelson Mandela.

Entendemos que essa vivência formativa foi bastante positiva para as educadoras, sobretudo, na sensibilização sobre a concepção de educação integral que compreende o desenvolvimento dos sujeitos em todas as suas dimensões (intelectual, física, emocional, social e cultural) e se constitui como projeto coletivo, compartilhado por crianças, jovens, famílias, educadores, gestores e comunidades locais. Portanto, supera uma visão de natureza estritamente compensatória e/ou de acolhimento social.

No Amazonas ainda são poucas as referências de experiências exitosas em educação integral em escolas públicas. Além disso, há alguns equívocos em torno das políticas de escola de tempo integral implantadas pela esfera estadual, cujas facetas são cada vez mais seletivas e classificatórias. Exemplo disso são as escolas públicas estaduais de ensino fundamental e médio repassadas à gestão da Polícia Militar que, focadas no uso de mais tempo para treinamento em vista dos resultados em exames externos, têm significado uma diferenciação prejudicial ao sistema de ensino local. Essas escolas de tempo integral, para além do seu projeto pedagógico conservador, baseado na ordem e na disciplina, têm recebido maior incentivo do estado para manutenção de sua estrutura física e das condições materiais de trabalho, num modelo de quase- 


\section{e-Curriculum}

Programa de Pós-Graduação em Educação: Currículo

privatização, inclusive com cobrança de taxas por meio das associações de pais e mestres. $\mathrm{O}$ foco acentuado na eficiência e seletividade tem seduzido muitos pais e mães que passam a disputar vagas nessas escolas e a apoiar esse modelo, convencidos da precarização das demais escolas públicas, da violência presente em seu cotidiano e diante da impossibilidade de matricularem seus filhos em escolas privadas (tradicionais) de maior prestígio. Esse fenômeno, pelo seu teor retrógrado, tem sido perturbador para todos nós do movimento que, assim como o educador Paulo Freire, apostamos na educação como prática de liberdade e como possibilidade de emancipação social. Por isso estamos na disputa de outros sentidos para a educação integral.

Conforme Arroyo (2012), considerando a importância de espaçostempos de um digno de viver da infância e da adolescência, há mais de três décadas movimentos e famílias lutam pela formulação de ações, programas e políticas públicas com base na educação integral, como forma de enfrentamento às muitas vulnerabilidades das crianças e adolescentes e ao aprimoramento contínuo da qualidade da aprendizagem. Os movimentos discutiam e ainda discutem questões como reorganização curricular; não fragmentação dos tempos, espaços e campos de saber; autonomia dos educandos na construção de seus percursos de aprendizagem; professores como mediadores do conhecimento; articulação comunitária e participação das famílias na gestão das instituições de ensino. Refletem, portanto, as pautas que vimos defendendo em nível local na exigência da (re)formulação e implementação da política de educação integral na rede pública de ensino de Manaus.

Uma de nossas táticas no aprofundamento desse diálogo foi a proposição da constituição de um grupo ampliado de trabalho no âmbito da SME envolvendo dirigentes e equipe técnica da Secretaria Municipal de Educação, gestores escolares, educadores, membros da comunidade, pesquisadores e membros do nosso coletivo para a reformulação da Proposta Pedagógica de Educação Integral do município e para acompanhamento/apoio técnico-pedagógico às escolas que passaram a funcionar em tempo integral. O grupo foi formalizado pela SME sob a designação de Comissão de Elaboração e Monitoramento da Educação Integral (conhecido como GT de Educação Integral), responsável pela elaboração da Proposta Pedagógica de Educação Integral para o Município de Manaus nos anos iniciais (MANAUS, 2016). Embora o documento não tenha abarcado a educação infantil, sutilmente deixando de fora o compromisso da SME com 


\section{e-Curriculum}

Programa de Pós-Graduação em Educação: Currículo

a educação integral para essa etapa ${ }^{\mathrm{ix}}$, consideramos que esse esforço colaborativo na formulação de um documento norteador para a educação integral na rede municipal de ensino significou um avanço importante. Até a presente data essa Comissão está em atividade, mas o desafio de maior envergadura foi verdadeiramente assumido pelo conjunto de educadores das três escolas municipais abarcadas pela política de educação integral no município a partir do ano de 2016.

No plano da organização interna do movimento, elaboramos o nosso estatuto e formalizamos a nossa associação. No final do ano de 2016, construímos um planejamento estratégico envolvendo três grandes eixos: Eixo I - Políticas Públicas e relações interinstitucionais; Eixo II - Formação continuada para subsidiar, embasar e difundir a construção de escolas democráticas e Eixo III - Fortalecimento e engajamento da comunidade escolar e ampliação da participação da sociedade civil. Respectivamente, assumimos os seguintes objetivos: 1) garantir a atuação do CEFA em rede na gestão municipal da educação para implementação da Escola Democrática e Integral (EDI) nas três escolas apoiadas; 2) desenvolver processos formativos envolvendo membros do CEFA, educadores e a comunidade com foco em EDI; e 3) articular escola e família ampliando espaços de diálogo e interação com a comunidade. Os desdobramentos das ações e as articulações entre esses três eixos de atuação estão em andamento, em processo constante de avaliação e de autocrítica do nosso ativismo, de modo a apoiar, mas não substituir, o protagonismo da comunidade escolar enquanto coletivo legítimo e autônomo, embora sejamos, no plano individual, membros dessas comunidades na qualidade de pais e mães de alunos/alunas das escolas apoiadas. É importante enfatizar que não pretendemos desresponsabilizar o poder público pela manutenção dessas escolas. Ao contrário disso, temos solicitado cada vez mais atenção, por exemplo, para a garantia de formação continuada dos/das educadores/educadoras (por meio de apoio pedagógico e da manutenção da Hora de Trabalho Pedagógico $-\mathrm{HTP}^{\mathrm{x}}$ ); para a autonomia das escolas na reformulação de seus Projetos Político-Pedagógicos e melhoria da infraestrutura das escolas e da merenda escolar.

\section{AS ESCOLAS MUNICIPAIS DE EDUCAÇÃO INTEGRAL (EM CAMPO ABERTO)}




\section{e-Curriculum}

Programa de Pós-Graduação em Educação: Currículo

Não há dúvida de que a escola é uma das instituições mais complexas da sociedade, caracterizando-se como um espaço de tensionamentos, de (re)produção e de (re)criação constantes. Para essa instituição, converge um conjunto de exigências e expectativas sociais, culturais e políticas quanto à formação de crianças, jovens e adultos e quanto à participação destes na sociedade, numa encruzilhada histórica entre "promessas" e "incertezas" (CANÁRIO, 2008).

No campo de disputa desse espaço público, é necessário questionar os discursos essencializantes sobre a precarização da qualidade da escola ao lado da flagrante tentativa de padronização e universalização do que deveria ser "um bom currículo" (de educação integral, inclusive). É oportuno, em várias esferas e por parte de muitos sujeitos, indagar em que medida a busca da padronização curricular pode representar uma contribuição real para a democratização do espaço escolar e para a valorização das políticaspráticas educacionais criadas nos cotidianos das escolas por seus praticantespensantes (OLIVEIRA, 2012).

Essas duas noções, cunhadas por Oliveira (2012), políticaspráticas e praticantespensantes, são fundamentais para a compreensão dos sentidos a serem evidenciados na atuação do nosso movimento, bem como na atuação cotidiana dos/das educadores/educadoras das/nas escolas. Originadas do conceito de praticantes (CERTEAU, 1994) e de uma visão epistemológica no sentido de superação da linha abissal (SANTOS, 2010), os termos citados buscam religar aquilo que é de fato indissociável. Não há prática que não seja política e o fazer não está dissociado do pensar. Assim, praticantespensantes tem a ver com os praticantes das escolas atuantes na criação cotidiana de seus currículos e de enredamentos de conhecimentos que se entrecruzam na tessitura dos saberes, sejam eles advindos das teorias ou aqueles aprendidos pelos praticantes em outros processos.

Essa margem da tessitura da/na criação cotidiana no contexto da escola se apresenta como resposta (ou resistências) às políticas educacionais de teor regulatório (aquelas que têm a pretensão de definir e padronizar o que deve ser a educação escolar, o currículo, as práticas das/dos professoras/professores etc.). Isso requer um esforço de crítica e autocrítica substancial de nossa parte. Hoje, são três as escolas a que o CEFA se vinculou e que se vincularam ao nosso movimento de pais e mães pela educação integral e democrática. Apesar de nossa intensa 


\section{$e$-Curriculum}

Programa de Pós-Graduação em Educaçãa: Currículo

participação como pais e mães de alunos/alunas e nas práticaspolíticas dentro e fora dessas escolas, não podemos descuidar do fato que o currículo da escola é criado cotidianamente e que seus praticantespensantes têm um papel preponderante nesse aspecto ${ }^{\mathrm{xi}}$.

É oportuno ressaltar essa crítica uma vez que a Proposta Pedagógica de Educação Integral, elaborada a partir dos trabalhos na Comissão de Elaboração e Monitoramento da Educação Integral da Secretaria Municipal de Educação, deve ser compreendida a partir de seu caráter provisório e apenas orientador na reformulação dos Projetos Político-Pedagógicos das escolas de educação integral. O que importa dizer é que muito do que a escola está criando, em parte com o nosso apoio, sobretudo no que diz respeito as suas práticas cotidianas curriculares, está em campo aberto e depende de muitos fatores como a criação de espaçotempo para que educadores/educadoras e a comunidade local discutam a educação que querem para seus/suas filhos/filhas e com eles/elas; o estímulo às práticas democráticas nas escolas; o aprofundamento da melhoria de suas condições físicas e materiais e apoio técnico, operacional e pedagógico por parte da SME, apenas para citar alguns.

Embora atuando fortemente nas três escolas apoiadas e em diálogo com os dirigentes da SME, temos clareza de que não seremos nós (por ação direta) ${ }^{\text {xii }}$ que transformaremos unilateralmente a cultura da escola ou que nos responsabilizaremos por sua manutenção. Apostamos, no entanto, na via do diálogo e da luta coletiva e colocamos em evidência a noção de autoridade partilhada como o alargamento da politização de todos os âmbitos da esfera social e que se materializa em práticas que tensionam e desvelam as relações de poderes (SANTOS, 1997) no dentrofora das escolas. Ainda que estejamos diante da invisibilização de muitas experiências sociais, implicando naquilo que esse autor chama de desperdício de experiência, a perspectiva de emancipação presente nas práticas cotidianas hoje em curso nas escolas apoiadas é fundamental para animar a nossa luta pela educação pública de qualidade.

Nessa perspectiva, Santos (1997) entende que é nas filigranas das práticas sociais que se pode ir em busca de um novo senso comum político para a elaboração de uma também nova cidadania, com a revalorização do princípio de comunidade (com a ideia de igualdade sem mesmidade, portanto, de valorização da diferença; a ideia de autonomia e a ideia de solidariedade). 


\section{e-Curriculum}

Programa de Pós-Graduação em Educação: Currículo

É nesse jogo de forças que se situa a luta do coletivo de pais e mães em Manaus pela qualidade da educação pública. Hoje, buscamos conhecer e articular experiências de educação democrática e transformadora em outros países da América Latina e entendemos que a articulação em rede, começando pelo Brasil, pode ser muito valiosa. Em maio de 2017, o CEFA participou do Congresso de Educação Democrática promovido pela Escuela Democratica de Humachuco, no Peru, onde se discutiu a necessidade dessa articulação em rede na América Latina, para que os projetos não sejam silenciados, gerando também um sistema de colaboração de luta e resistência. Inspirados por outras várias práticas democráticas de educação, também idealizamos conjuntamente com o Coletivo Construindo o Saber (localizado em Niterói - RJ) um curso de (des)formação docente, independente e autogestionado pelos participantes, intitulado Amã (palavra de origem Tupi-Guarani que designa "envolver"). Esclareço que essa (des)formação é pensada no sentido de desaprendizagens, muito alinhada à ecologia de saberes ${ }^{\text {xiii }}$ proposta por Santos (2010), considerando que a ignorância é também um ponto de chegada num processo de aprendizagens recíprocas.

\section{FINALIZANDO...}

Considerando que a experiência aqui relatada ainda se encontra em processo, mas que já representa para os integrantes do movimento, bem como para educadoras/educadores, dirigentes, estudantes e comunidade em geral uma oportunidade promissora de diálogo e de negociação da qualidade da educação (a qual almejamos emancipatória e socialmente referenciada), apresentamos algumas falas ${ }^{\text {xiv }}$ das crianças (estudantes, filhos/filhas ou não de integrantes do movimento) que refletem as mudanças que vêm ocorrendo nas escolas apoiadas por nós.

A gente tentou várias escolas e não estava dando certo. Até que a gente teve a ideia de fazer uma escola. Quando digo fazer não [é] com tijolos, é fazer programando ela! (João Bocchini, 6 anos, estudante da EMEF Maria das Graças Vasconcelos)

Antes, na escola antiga, a gente passava o dia inteiro estudando as mesmas matérias que a gente estudava de manhã e, tipo, era muito repetitivo, sabe, cansativo! (...) Eu solicitaria uma visita de outras escolas para perceberem que o 


\section{e-Curriculum}

Programa de Pós-Graduação em Educação: Currículo

método de ensino aqui mudou. As aulas agora são diferenciadas e muito boas, eu achei. É muito legal fazer isso aqui e eu gostaria que outros alunos tivessem esse prazer pelas aulas e pela a sua escola. (João Paulo Andrade, 9 anos, estudante da EMEF Prof. Waldir Garcia)

No primeiro dia as professoras estavam explicando lá no teatro. Daí, como é uma escola democrática, a gente participa das coisas. Isso faz a nossa escola ser diferente. Tem crianças que limpam a sala com vassoura (...); tem um pai que faz jiu-jitsu aqui e fazemos educação física. (João Bocchini, 6 anos, estudante da EMEF Maria das Graças Vasconcelos)

Antigamente os professores, tipo assim, as autoridades da escola não davam ouvidos pra gente, eram as ordem deles (...) eles não ouviam a gente e a gente pensava "ah, que chato!". A gente tinha que ir porque era obrigatório. Agora eles estão dando mais ouvidos pra gente, tipo na assembleia. (Gabriel Brancho, 11 anos, EMEF Prof. Waldir Garcia)

Acho que a postura deles mudou porque eles ainda não haviam trabalhado numa escola de educação integral com essas mudanças. (Milena Tenazor, 10 anos, EMEF Prof. Waldir Garcia)

Essas falas expressam para nós a esperança na transformação da educação e na valorização do seu caráter público. Elas apontam para a educação pública como um projeto que deve ser pensado coletivamente e no qual as transformações devem contar com a participação de todos os sujeitos que fazem parte da escola/sociedade. As falas das crianças não apenas tornam visíveis as mudanças ocorridas, mas também podem sugerir uma maior articulação da sociedade com as políticas públicas educacionais e de atenção à infância.

Ao eleger essas passagens, gostaríamos também dizer que saber escutar as crianças é fundamental para além do espaço doméstico e isso inclui considerar as suas vozes no nosso movimento e no repensar de políticas públicas que devem ser formuladas com elas e para elas. 


\section{e-Curriculum}

Programa de Pós-Graduação em Educação: Currículo

\section{REFERÊNCIAS}

ALVES, Nilda. Decifrando o pergaminho - os cotidianos das escolas nas lógicas das redes cotidianas. In: OLIVEIRA, Inês Barbosa.; ALVES, Nilda. (Org.). Pesquisa nos/dos/com os cotidianos das escolas. 3. ed. Petrópolis, RJ: DP et alii, 2008. p. 15-38.

ARROYO, Miguel. O direito a tempos-espaços de um justo e digno viver. In. MOLL, Jaqueline. et. al. Caminhos da educação integral no Brasil: direito a outros tempos e espaços educativos. Porto Alegre: Penso, 2012. p. $33-45$.

BRASIL. Lei N ${ }^{\circ}$ 13.005, de 25 de junho de 2014. Aprova o Plano Nacional de Educação - PNE e dá outras providências, Brasília, 2014.

CANÁRIO, Rui. Escola: das "promessas" às "incertezas". In: Educação Unisinos. Ano. 12, vol. 2, maio/agosto. 2008. p. 73-81.

CERTEAU, Michel. de. A invenção do cotidiano 1: artes de fazer. Petrópolis, RJ: Vozes, 1994.

MANAUS. Lei No 10.000 de 24 de junho de 2015. Aprova o Plano Municipal de Educação, Manaus, 2015.

MANAUS. SECRETARIA MUNICIPAL DE EDUCAÇÃO - SME. Proposta Pedagógica de Educação Integral para o Município de Manaus nos anos iniciais, 2016.

MASSCHELEIN, Jan; SIMONS, Maarten. A pedagogia, a democracia, a escola. Belo Horizonte: Autêntica, 2014 - (Col. Educação: Experiência e Sentido).

OLIVEIRA, Inês Barbosa. de. O currículo como criação cotidiana. Petrópolis, RJ: DP et alii; Rio de Janeiro: FAPERJ, 2012.

SANTOS. Boaventura de Sousa. Pela mão de Alice - O social e o político na Pós-Modernidade. 4. ed. São Paulo: Cortez, 1997.

SANTOS. Boaventura de Sousa. Conhecimento prudente para uma vida decente: um discurso sobre a ciência revisitado. São Paulo: Cortez, 2004.

SANTOS, Boaventura de Sousa. Para além do pensamento abissal: das linhas globais a uma ecologia de saberes. In: SANTOS, Boaventura de Sousa; MENESES, Maria Paula. (Org.). Epistemologias do Sul. São Paulo: Cortez, 2010. p. 31-83. 


\section{$e$-Curriculum}

Programa de Pós-Graduação em Educaçãa: Currículo

STRECK. Danilo. Entre emancipação e regulação: (des)encontros entre educação popular e movimentos sociais. In: Revista brasileira de Educação. v.15, n. 44; mai/ago. 2010. p. 300-310.

Notas

${ }^{\mathrm{i}}$ Fragmento do texto transcrito do vídeo "Tempo de viver sem medo", com o referido escritor. Acesso em 12 de agosto de 2017:<https://youtu.be/GrplviKwbr8>.

${ }^{\text {ii } O s ~ n e o l o g i s m o s ~ a q u i ~ g r a f a d o s ~ e m ~ i t a ́ l i c o ~ s e ~ a p r e s e n t a m ~ c o m o ~ u m ~ r e c u r s o ~ e m p r e g a d o ~ p e l o s ~ e s t u d i o s o s ~ d o s / n o s / c o m ~}$ os cotidianos e proposto por Alves (2008) como modo de romper com dicotomias ou cisões elaboradas pelo pensamento moderno e como possibilidade de produzir novos sentidos para aquilo que costumeiramente fomos levados a perceber de forma fragmentada. Trata-se, portanto, de um exercício de pensamento sobre as palavras e o que elas podem nos sugerir quando apresentadas integradamente.

iii Trata-se do Coletivo Escola Família Amazonas - CEFA.

${ }^{\text {iv }}$ A maioria dos integrantes deste movimento é constituída por pesquisadores, professores de universidades públicas e/ou ambientalistas atuantes em organizações não governamentais. Estes últimos, especialmente, têm experienciado práticas de conselhos comunitários e também modos de vida que enfatizam ações mais colaborativas em comunidade, agregando essas perspectivas ao interior do movimento e, sem dúvida, isso tem enriquecido as nossas práticas no coletivo.

vApós o seminário foram realizadas visitas às escolas municipais, cerca de 20 ou mais, pelos membros do coletivo para conhecer essas escolas e conversar com os/as educadores/educadoras, procurando identificar as potencialidades e desafios em cada uma delas.

${ }^{\mathrm{vi}} \mathrm{O}$ Cine-CEFA itinerante foi uma dessas estratégias. A proposta era levar a diversos espaços (escolas, universidades e associações) filmes sobre educação para serem exibidos e discutidos abertamente. Outra iniciativa foi a criação de um site para divulgação de textos e atividades (www.cefa.net.br) e de um perfil nas redes sociais.

${ }^{\text {vii }}$ Ver em http://educacaointegral.org.br/

viii Trata-se da EMEF Prof. Waldir Garcia, com cerca de 30 anos de existência, localizada em um bairro próximo à zona central em intensa mudança demográfica em razão de um programa de saneamento do governo do estado que removeu centenas de famílias do entorno do igarapé próximo da escola, fazendo cair a matrícula de alunos entre 2014 a 2015 em dois terços da sua capacidade de atendimento.

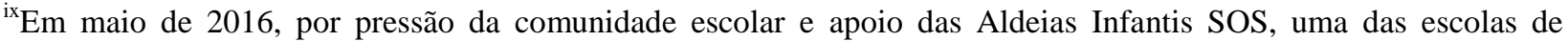
educação infantil passou a funcionar em tempo integral para o Maternal III (crianças de três anos). Em 2016, a Secretaria não apenas extinguiu o Maternal III, como também o período integral, para que houvesse vagas para as crianças de quatro e cinco anos, idade obrigatória para oferta do município.

${ }^{x}$ Os profissionais da Educação Infantil, no sistema educacional de Manaus, não têm garantida a HTP.

${ }^{x i}$ Parte das mudanças ocorridas no interior das escolas que apoiamos foi captada num dos episódios da web-série “O que eles têm a nos dizer?", produzida pelo Coletivo [Re]Considere, dedicada à documentação de experiências de educação democrática em escolas da América Latina. A web-série resulta de uma viagem que durou seis meses em contato com experiências na Argentina, Brasil, Peru, Colômbia e Bolívia. Ver: https://www.youtube.com/user/coletivoreconsidere

${ }^{\text {xii }}$ Temos realizado algumas ações no campo da formação continuada dos/das educadores/educadoras das escolas apoiadas; na realização de mutirões para a melhoria das instalações das escolas; em atividades coletivas (festas, bazares, horta escolar, passeios com as crianças); na luta pela melhoria da merenda escolar etc.

Ceane ANDRADE,Ana Gouvea BOCCHINI, Regina Coeli Moura de MACEDO O movimento de pais e mães pela ecucação integral em Manaus: articulando a pesquisa nos/dos/com os cotidianos com a luta por uma educação de qualidade socialmente referenciadal. 


\section{e-Curriculum}

Programa de Pós-Graduação em Educaçãa: Currículo

xiii Conforme Santos (2010), ecologia de saberes decorre de um diálogo horizontal entre conhecimentos que resistem com êxito às relações desiguais de saber-poder que têm suprimido ou invisibilizado muitas formas de saber próprias dos povos. Para esse pensador, conhecimento é interconhecimento.

${ }^{\text {xiv }}$ Falas extraídas do episódio 5 da web-série “O que eles têm para nos dizer?", produzida pelo Coletivo [Re]Considere, sobre as mudanças nas/das escolas apoiadas pelo CEFA. Acesso em 12 de agosto de 2017: <https://youtu.be/cOVBIQDIRFw>

Artigo recebido em 10/10/2017. Aceito para publicação em 21/12/2017. 